\title{
Seroprevalencia de Neospora caninum en un Hato Lechero de Boyacá, Colombia
}

\author{
Seroprevalence of Neospora caninum in a Dairy Herd in Boyacá, Colombia \\ Martín Orlando Pulido-Medellín ${ }^{1,2}$, Diego José García-Corredor', \\ Julio Cesar Vargas-Abella ${ }^{1}$
}

\section{Resumen}

El presente estudio tuvo como objetivo determinar la presencia de anticuerpos contra Neospora caninum en un hato lechero del municipio de Toca, Colombia. Se tomaron 100 muestras de sangre de bovinos de 1 a 9 años de edad, seleccionados mediante un método aleatorio simple de corte transversal prospectivo. Las muestras de suero fueron procesadas mediante un kit comercial de ELISA indirecta. La seroprevalencia de anticuerpos anti- $N$. caninum fue de $64 \%$. La asociación entre animales positivos con historia de abortos y número de partos fue estadísticamente significativa $(\mathrm{p}<0.05)$, en tanto que la asociación con la edad, estado reproductivo y repetición de celos no fue significativa.

Palabras clave: neosporosis, ELISA, aborto, prevalencia

\section{AbSTRact}

The aim of the present study was to determine the presence of antibodies against Neospora caninum in a dairy herd in the municipality of Toca, Colombia. Blood samples $(n=100)$ were collected from females between 1 and 9 years of age. The animals were selected through simple random method of prospective cross-cut. The serum samples were processed using a commercial indirect ELISA kit. The prevalence of antibodies anti$N$. caninum was $64 \%$. The association between positive animals with history of abortion

\footnotetext{
${ }^{1}$ Grupo de Investigación GIDIMEVETZ, Laboratorio de Parasitología Veterinaria, Programa de Medicina Veterinaria y Zootecnia, Universidad Pedagógica y Tecnológica de Colombia, Colombia

${ }^{2}$ E-mail:mopml@hotmail.com
}

Recibido: 1 de octubre de 2015

Aceptado para publicación: 6 de marzo de 2016 
and parity was statistically significant $(\mathrm{p}<0.05)$, while the association with age, reproductive status and repeat breeding was not significant.

Key words: neosporosis, ELISA, abortion, prevalence

\section{INTRODUCCIÓN}

La neosporosis bovina se perfila en Colombia y el mundo como una importante enfermedad reproductiva causante de elevadas pérdidas económicas y productivas (Dubey et al., 2007; Kamali et al., 2014), habiéndose estimado pérdidas superiores a 80 millones de dólares anuales en Argentina (Campero et al., 2000; Lértora et al., 2010).

Diversos estudios a nivel internacional han sido llevados a cabo para determinar los efectos negativos que implica la presencia de $N$. caninum en los hatos bovinos (Dubey y Schares, 2006; Escalona et al., 2010; Nasir et al., 2012, Weifeng et al., 2015). En Colombia no se dispone de estimaciones reales acerca de las pérdidas económicas por Neospora, pero ya se han desarrollado mapas epidemiológicos regionales, encontrando frecuencias variables de acuerdo a la zona muestreada. Por ejemplo, en Montería se reportó la presencia de $N$. caninum en el $10.2 \%$ de las fincas analizadas (Oviedo et al., 2007), en tanto que en la sabana de Bogotá, Nariño, y en algunas zonas cálidas se encontró $54.1 \%$ de seropositividad (Zambrano-Varón y Thurmond, 2009).

Si bien es cierto, el número de muestras analizadas en algunas regiones es bastante limitada, los datos obtenidos dan un estimado alarmante de la situación nacional con respecto a la neosporosis bovina. Por lo pronto, en Boyacá se han realizado algunas investigaciones (Andrade et al., 2007; Pulido et al., 2013) que ha permitido elaborar un mapa epidemiológico de la enfermedad para esta zona, el cual facilitará estudios relacionados con la patogénesis y cálculos económicos de pérdidas atribuidas a este fenómeno.

Por esta razón se desarrolló el presente estudio con el fin de determinar la seroprevalencia de anticuerpos contra $N$. caninum mediante la técnica de ELISA en bovinos de un hato lechero del municipio de Toca, Colombia, así como evaluar posibles variables que pueden estar asociadas con la neosporosis.

\section{Materiales y Métodos}

\section{Tipo de Estudio}

Esta investigación correspondió a un estudio descriptivo de corte transversal con muestreo aleatorio y distribución proporcional al tamaño de la muestra.

\section{Localidad y Animales}

El estudio se desarrolló en el municipio de Toca, departamento de Boyacá, Colombia. El municipio tiene un área de $165 \mathrm{~km}^{2}$, se encuentra a una altitud de $2810 \mathrm{~m}$, está conformado por una topografía variable entre valles y montañas y posee una temperatura media de $13{ }^{\circ} \mathrm{C}$ (Alcaldía Municipal de Toca, 2015).

La población de referencia fue de bovinos hembras de raza Holstein pertenecientes a una finca ganadera de la vereda «Raiba». La finca se especializa en la producción de leche en un sistema de explotación extensivo con un promedio de producción de 12.5 litros/vaca/día. Utiliza inseminación artificial y 
presenta evidentes problemas reproductivos (bajo porcentaje de fertilidad y alta presencia de abortos). La finca tenía 134 bovinos donde fueron seleccionados el $75 \%(\mathrm{n}=100)$, según tamaño de muestra para un $95 \%$ de confianza. Se registró la edad (1-9 años), número de partos y estado reproductivo, historia de abortos y tipo de celos de cada animal tomados del registro de manejo reproductivo de la finca. No hubo presencia de perros en la finca.

El diagnóstico de preñez empleado en la finca se realiza por ecografía cada 21 días en los animales que no muestran signos de celo posteriores a la inseminación.

\section{Recolección y Procesamiento de Mues- tras}

Se recolectaron muestras de sangre (7 ml) mediante venopunción coccígea en tubos al vacío (tipo Vacutainner) sin anticoagulante. Las muestras fueron transportadas bajo refrigeración en cavas de poliestireno expandido al laboratorio de Parasitología Veterinaria de la Universidad Pedagógica y Tecnológica de Colombia en un tiempo menor a dos horas.

En el laboratorio, las muestras fueron centrifugadas a $1500 \mathrm{rpm}$ durante $10 \mathrm{minu}$ tos y el suero resultante fue transferido a un tubo de almacenamiento. Las muestras se procesaron bajo la técnica de ELISA indirecta (Camillo et al., 2010; Sierra et al., 2011) para la detección de anticuerpos contra Neospora caninum, utilizando un kit comercial (Ingezim Neospora ${ }^{\circledR}$, Ingenasa, España). Para la determinación de muestras positivas y negativas se siguió el instructivo del kit.

\section{Análisis de Resultados}

Se consideraron las edades por meses equivalentes a cada año de edad para determinar el número de bovinos con anticuerpos anti- $N$. caninum. Se aplicó la técnica esta- dística de Chi Cuadrado de bondad de ajuste con el programa Epi Info para determinar posible diferencia estadística entre las frecuencias de individuos infectados y no infectados con N. caninum. Asimismo, se empleó la prueba de comparación múltiple de proporciones utilizando el programa CompaProWin 2.0 para determinar posibles asociaciones de la seroprevalencia con las variables edad, número de partos, ocurrencia de celos (vacas con celos regulares, vacas repetidoras), estado reproductivo (preñada, vacía) e historia de abortos (sí, no).

\section{Resultados}

Se encontró una prevalencia de $64 \%$, donde la presencia de mayor número de vacas con el anticuerpo anti $N$. caninum fue significativa $\left(\left(\mathrm{c}^{2}=7.84, \mathrm{p}=0.0051\right)\right.$. No hubo diferencia estadística por edades en la proporción de vacas con anticuerpos anti- $N$. caninum $(\mathrm{p}=0.4289)$ (Figura 1).

La presencia de $N$. caninum fue independiente del estado reproductivo de los animales ( $\mathrm{p}=0.8025$ ), observándose $33 \%$ de seropositividad (33/64) en hembras vacías y de $31 \%$ en el caso de hembras preñadas (31/64); asimismo, tampoco se observó diferencia estadística entre animales con celos regulares y aquellos con repetición de celos $(\mathrm{p}=0.2113)$ (Figura 2).

Se encontró una mayor y significativa frecuencia de animales seropositivos con historia de abortos $(46 \%)$ que en aquellos sin registros de abortos $(18 \%)(\mathrm{p}=0.0005)(\mathrm{Fi}-$ gura 2).

Los animales con 3 o menos partos presentaron una menor proporción de seropositividad $(44 / 73,60.3 \%)$ que animales con animales con más de 3 partos (20/27, $74.1 \%)$, siendo significativa esta diferencia $(\mathrm{p}=0.0027)($ Figura 3$)$. 


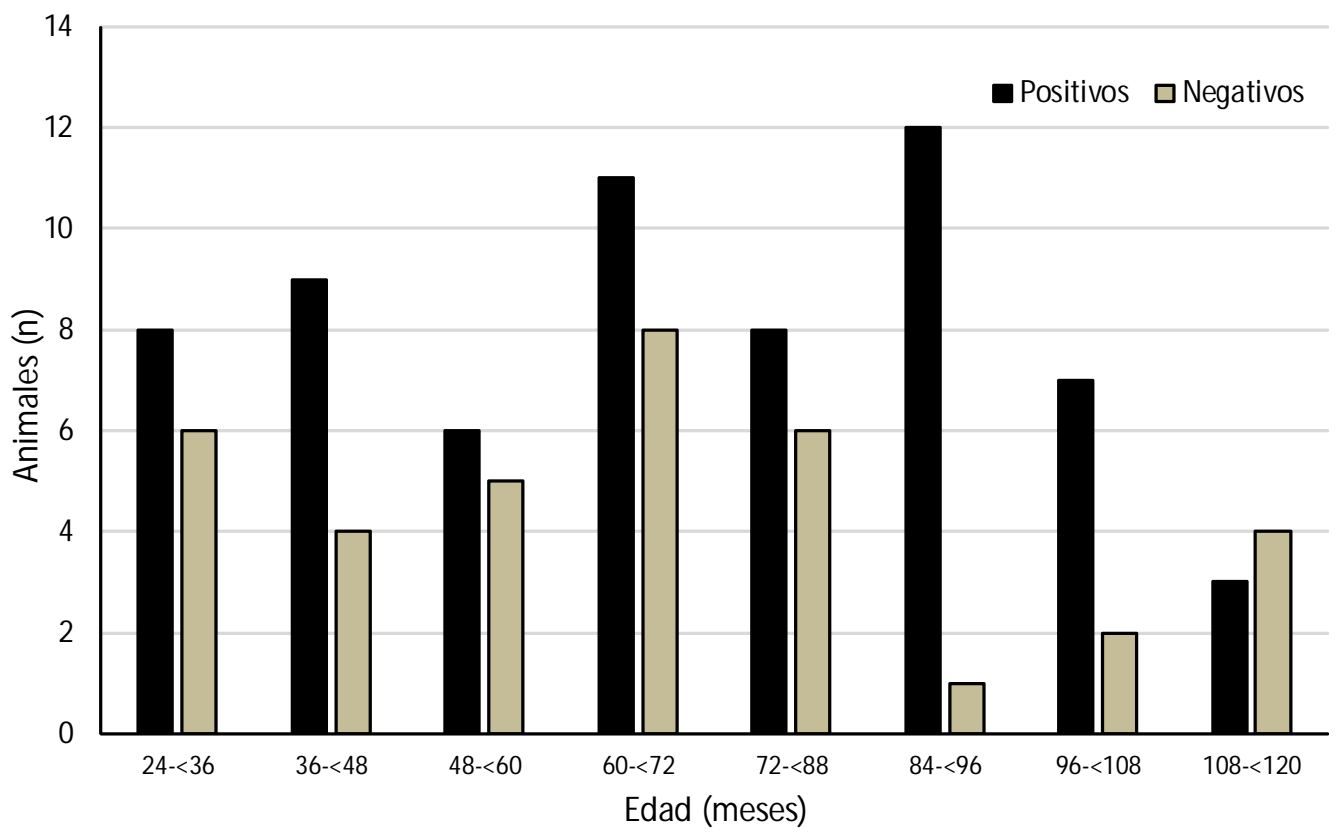

Figura 1.Frecuencia de bovinos con anticuerpos anti- $N$. caninum según edad

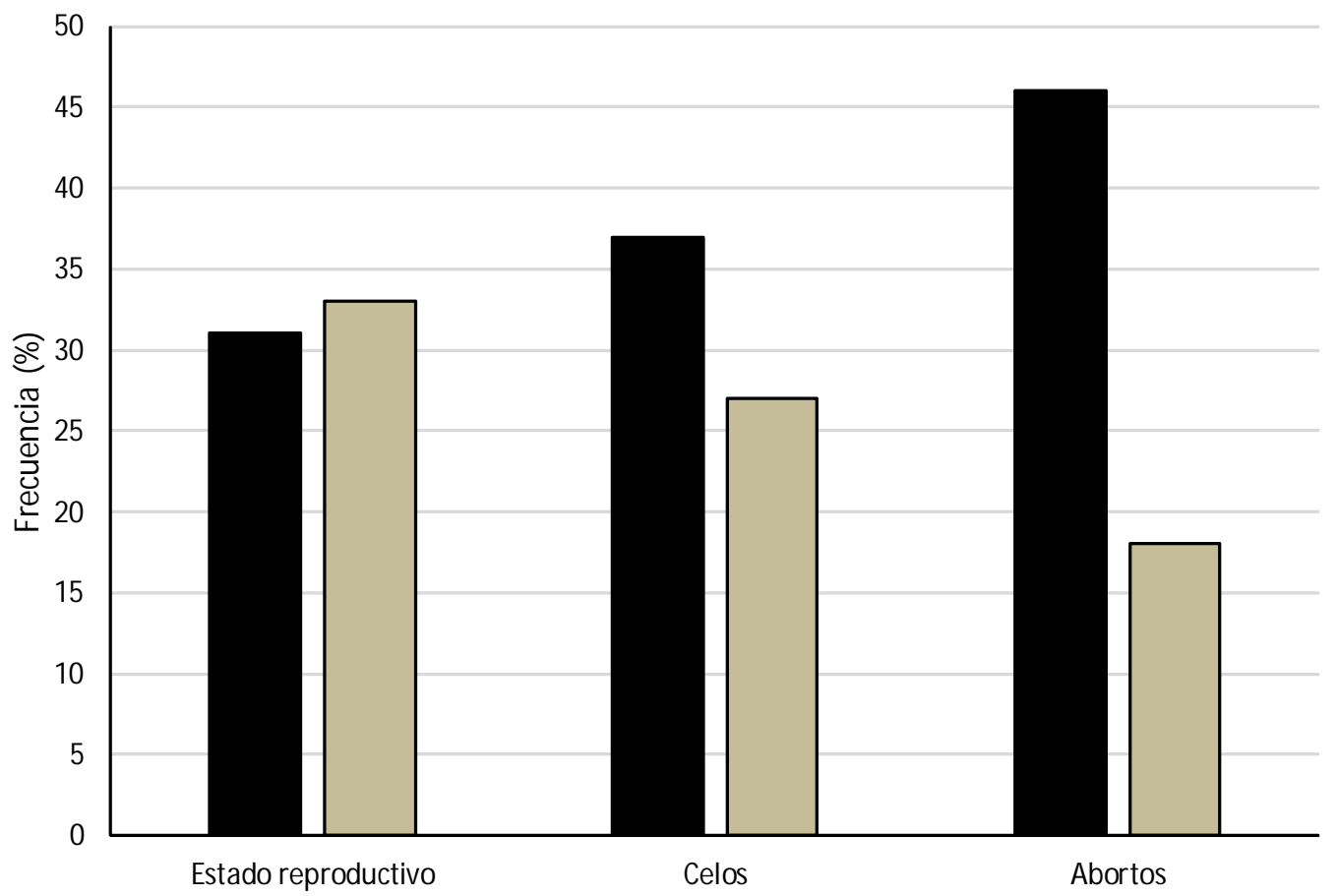

Figura 2. Prevalencia de bovinos con anticuerpos anti-N. caninum, según el estado reproductivo (preñada, vacía), manifestación de celos (regulares, vacas repetidoras) e historia de abortos (con y sin historia) 


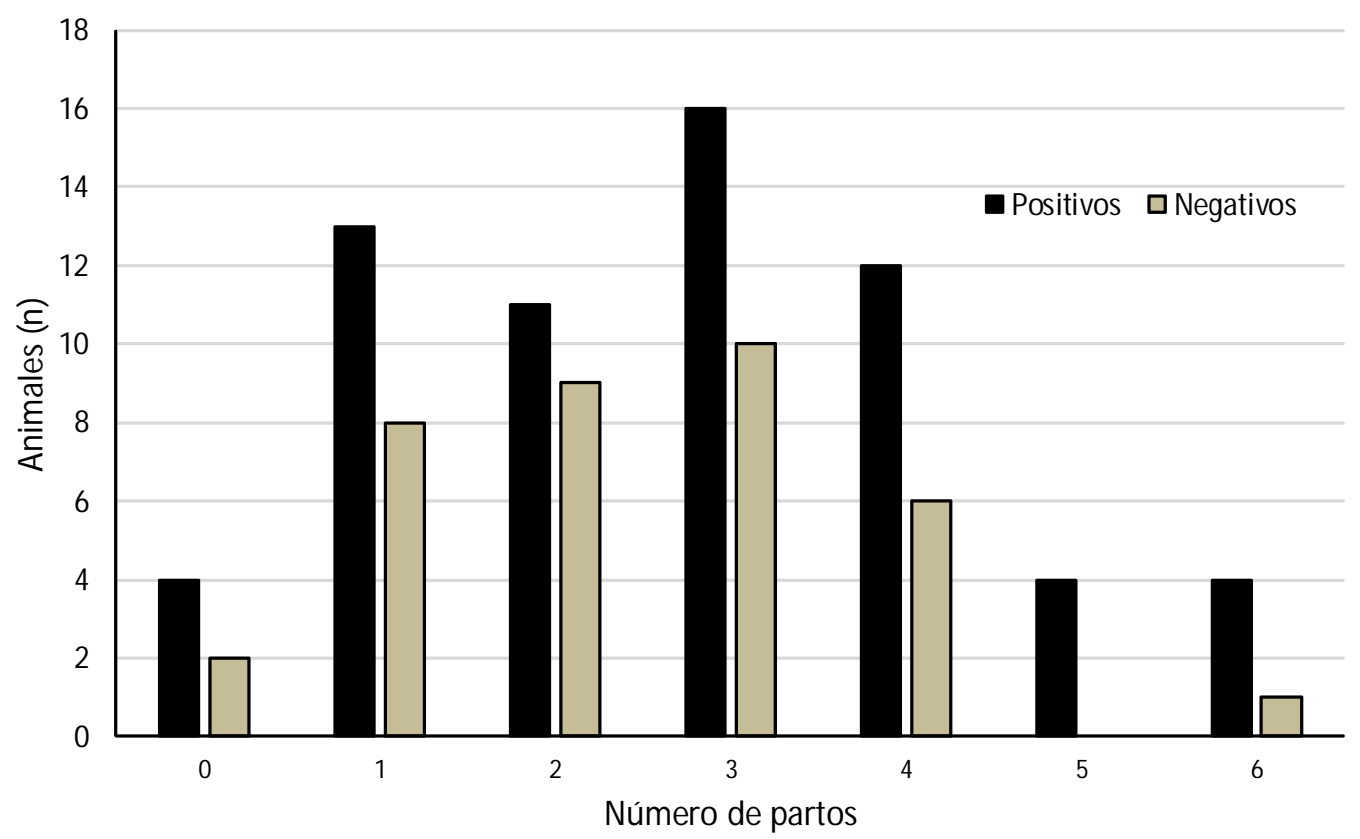

Figura 3. Frecuencia de vacas y novillas con anticuerpos anti- $N$. caninum según número de parto

\section{Discusión}

El $64 \%$ de prevalencia de anticuerpos contra $N$. caninum indica que estos animales fueron expuestos al parásito en algún momento de la etapa pre o postnatal (Mello et al., 2008; Escalona et al., 2010). La alta prevalencia de $N$. caninum encontrada en bovinos de producción extensiva sugiere la presencia de factores que contribuyen a la transmisibilidad o persistencia del parásito en los bovinos susceptibles (Obando et al., 2010; Jianhua et al., 2014; Chunmei et al., 2015).

En Colombia se conocen pocos estudios acerca de la presencia de $N$. caninum en hatos lecheros. Entre estos, López et al. (2007), Oviedo et al. (2007) Cedeño y Benavides (2013) encontraron prevalencias de $34.6,10.2$ y $76.9 \%$, respectivamente; mientras que en otros países se han reportado prevalencias que van desde 2.7 a $44 \%$ (Ghalmi et al., 2012; Sanhueza et al., 2013; Salant et al., 2015).
Uno de factores que pueden influir la diseminación de la enfermedad se encuentra la infección transplacentaria a las crías, donde el mantenimiento de vacas positivas con enfermedad postnatal perpetúa la presencia del parásito en los hatos, convirtiendo fincas enteras en seropositivas a $N$. caninum (Sbruzzi et al., 2012; Goodswen et al., 2013).

La importancia de la prevalencia encontrada en este estudio radica en el hecho de que a mayor seropositividad de animales en el hato mayor serán los niveles de transmisión vertical, tal como se demuestra en un estudio hecho en Brasil, donde se describió un alto grado de correlación entre la tasa de transmisión vertical y la prevalencia de animales seropositivos (Camillo et al., 2010).

Un aspecto importante en este estudio fue la presencia del parásito, tanto en vacas gestantes como vacías. Esto podría deberse a que la mayoría de vacas infectadas tienen gestaciones normales; sin embargo, las vacas positivas tienen mayor probabilidad de 
abortar que aquellas negativas, especialmente si se infectan en el primer tercio de la gestación (Chunmei et al., 2015). Es posible que esta variable no posea relación directa con la presencia del parásito pero si tiene relación con el principal evento reportado en vacas infectadas que es el aborto (Obando et al., 2010; Kamali et al., 2014).

Se determinó la presencia de anticuerpos anti- $N$. caninum en vacas con 0 a 6 partos; sin embargo, se evidenció una menor presentación de anticuerpos en hembras con historial de tres o menos partos (44/73). Estos resultados se deben posiblemente a que los animales son infectados desde temprana edad y los títulos de anticuerpos contra $N$. caninum se mantienen elevados por años (Ghalmi et al., 2012; Jianhua et al., 2015). Además de esto, una exposición reciente al parasito se puede evidenciar en una seroconversión y aumento de anticuerpos, pero no necesariamente en un aumento de la tasa de abortos. Esto apoya la hipótesis de que además de la infección existen otros factores que pueden influir en el riesgo de aborto como bacterias (Leptospira sp, Campylobacter sp) y enfermedades virales (IBR, DVB) (O’ Doherty et al., 2015).

\section{Conclusiones}

- La seroprevalencia de anticuerpos anti$N$. caninum fue de $64 \%$ en un hato lechero del municipio de Toca, Colombia).

- La asociación entre animales positivos con la historia de abortos y el número de partos fue estadísticamente significativo $(\mathrm{p}<0.05)$, en tanto que la asociación con la edad, estado reproductivo y repetición de celos no fue significativa.

\section{Literatura Citada}

1. Alcaldía Municipal de Toca. Información geográfica del municipio de Toca. 2015. [Internet]. Disponible en: http://www.toca-boyaca.gov.co/ informacion_general.shtml\#geografia

2. Andrade $R$, Pulido M, Caycedo A, López J. 2007. Análisis prospectivo de la seropositividad de Neospora caninum en ejemplares bovinos de raza Holstein de una finca lechera en Toca, Boyacá (Colombia). Rev Col Cienc Pec: 20(4): 557.

3. Camillo G, Cadore G, Cezar AS, Toscan G. 2010. Anticorpos antiNeospora caninum em bovinos de leite do sudoeste do estado do Paraná. Arq Bras Med Vet Zootec 62: 1511-1513. doi: 10.1590/S0102-09352010000600033

4. Campero CM, Cipolla AL, Odeón AC, Odriozola E, Moore DP, Ronchi J. 2000. Causales del aborto y mortalidad neonatal en bovinos de la provincia de Buenos Aires, Argentina. XXI Congreso Mundial de Buiatria, Punta del Este, Uruguay.

5. Cedeño D, Benavides B. 2013. Seroprevalence and risk factors associated to Neospora caninum in dairy cattle herds in the municipality of Pasto, Colombia. Rev MVZ Córdoba 18: 3311-3316.

6. Chunmei Jin, Longzheng Yu, Yinan Wang, Shiyue Hu, Shoufa Zhang. 2015. Evaluation of Neospora caninum truncated dense granule protein 2 for serodiagnosis by enzyme-linked immunosorbent assay in dogs. Exp Parasitol 157: 88-91. doi: 10.1016/ j.exppara.2015.07.003

7. Dubey JP, Schares G, Ortega-Mora LM. 2007. Epidemiology and control of Neosporosis and Neospora caninum. Clin Microbiol Rev 20: 323-367. doi: 10.1128/CMR.00031-06

8. Dubey JP, Schares G. 2006. Diagnosis of bovine neosporosis. Vet Parasitol 140: 1-34. doi: 10.1016/j.vetpar.2006.03.035

9. Escalona J, García F, Mosquera O, Vargas F, Corro A. 2010. Factores de riesgo asociados a la prevalencia de neosporosis bovina en el municipio Bolívar del estado Yaracuy, Venezuela. Zootecnia Trop 28: 201-212. 
10. Ghalmi F, China, B, Ghalmi A, Hammitouche D, Losson B. 2012. Study of the risk factors associated with Neospora caninum seroprevalence in Algerian cattle populations. Res Vet Sci 93: 655-661. doi: 10.1016/j.rvsc.2011. 12.015

11. Goodswen S, Kennedy P, Ellis J. 2013. A review of the infection, genetics, and evolution of Neospora caninum: from the past to the present. Infect Genet Evol 13: 133-150. doi: 10.1016/j.meegid. 2012.08.012

12. Jianhua Li, Pengfei Hea, Yanhui Yua, Ling Dua, Pengtao Gonga, Guocai Zhanga, Xichen Zhang. 2014. Detection of Neospora caninum-DNA in feces collected from dogs in Shenyang (China) and ITS1 phylogenetic analysis. Vet Parasitol 205: 361-364. doi: 10.1016/ j.vetpar.2014.06.036

13. Kamali A, Seifi HA, Movassaghi AR, Razmi GR, Naseri Z. 2014. Histopathological and molecular study of Neospora caninum infection in bovine aborted fetuses. Asian Pac J Trop Biomed 4: 990-994. doi: 10.12980/ APJTB.4.201414B378

14. Lértora JD, Mohr-Betania N, Mosqueda MG Sánchez-Negrette M. 2010. Detección de Neospora caninum en fetos bovinos abortados espontáneamente en el nordeste Argentino. InVet 12: 173-182.

15. López G, Restrepo B, Restrepo M, Lotero M, Murillo V, Chica A, Cano J, Giraldo J. 2007. Estudio para evidenciar la presencia de Neospora caninum en bovinos de la hacienda San Pedro en el municipio de Fredonia. Rev MVZ CES 2(1): 7-20.

16. Mello R, Andreotti R, Barros J, Tomich $R$, Mello A, Campolim A, Pellegrin A. 2008. Levantamento epidemiológico de Neospora caninum em bovinos de assentamentos rurais em Corumbá, MS. Rev Bras Parasitol Vet 17 (Supl 1): 311-316.
17. Nasir A, Lanyon S, Schares G, Anderson M, Reichel M. 2012. Seroprevalence of Neospora caninum and Besnoitia besnoiti in South Australian beef and dairy cattle. Vet Parasitol 186: 480- 485. doi: 10.1016/j.vetpar.2011. 11.032

18. Obando C, Bracamonte M, Montoya A, Cadena V. 2010. Neospora caninum en un rebaño lechero y su asociación con el aborto. Rev Cient FCVLUZ 20: 235-239.

19. O' Doherty E, Sayers $R, O^{\prime}$ Grady L, Shalloo L. 2015. Effect of exposure to Neospora caninum, Salmonella, and Leptospira interrogans serovar Hardjo on the economic performance of Irish dairy herds. J Dairy Sci 98: 2789-2800. doi: 10.3168/jds.2014-8168

20. Oviedo TS, Betancur CH, Mestra AP, González MT, Reza LG, Calonge KG. 2007. Estudio serológico sobre neosporosis en bovinos con problemas reproductivos en Montería, Córdoba, Colombia. Rev MVZ Córdoba 12: 929-933.

21. Pulido Medellín MO, Díaz Anaya AM, Garcia DJ, Andrade Becerra RJ. 2013. Determinación de anticuerpos anti Neospora caninum en vacas de la provincia de Sugamuxi, Colombia. Rev Mex Cienc Pec 4: 501-506.

22. Salant H, Mazuz ML, Savitsky I, Nasereddin A, Blinder E, Baneth $G$. 2015. Neospora caninum in cows from Israel. Vet Parasitol 212: 375-378. doi: 10.1016/j.vetpar.2015.08.019

23. Sanhueza JM, Heuer C, West D. 2013. Contribution of Leptospira, Neospora caninum and bovine viral diarrhea virus to fetal loss of beef cattle in New Zealand. Prev Vet Med 112: 90-98. doi: 10.1016/j.prevetmed.2013.07.009

24. Sbruzzi JM, Amaku M, Urias-dosSantos AJ, Gennari SM. 2012. A longitudinal study of Neospora caninum 
infection on three dairy farms in Brazil. Vet Parasitol 187: 553-557. doi: 10.1016/ j.vetpar.2012.01.019

25. Sierra R, Medina-Esparza $C$, Ramos Parra L, García-Vázquez Z, CruzVázquez C. 2011. Factores de riesgo asociados a la seroprevalencia de anticuerpos a Neospora caninum en ganado lechero de Aguascalientes, México. Rev Mex Cienc Pec 2(1): 15-24.
26. Weifeng Qian, Hui Wang, Dan Shan, Bo Li, Jing Liu, Qun Liu. 2015. Activity of several kinds of drugs against Neospora caninum. Parasitol Int 64: 597-602. doi: 10.1016/j.parint. 2015. 08.002

27. Zambrano-Varón J, Thurmond M. 2009. Aproximación epidemiológica para medir y entender el aborto bovino. Rev Med Vet Zoot 56: 309-326. 